\title{
Some Significant Trends in The Antimicrobial Treatment of Silk
}

\author{
K Sangeetha, S Umamageshwari, M Bhuvaneshwari, E Devaki, R Pragadeeswari, Christie Jenifer and \\ N Gokarneshan* \\ Department of Textiles and Apparel design, Bharathiar University, India
}

*Corresponding author: N Gokarneshan, Department of Textile Technology, Bannariamman Institute of Technology,

Sathyamangalam, Tamil Nadu, India

\begin{tabular}{l} 
ARTICLE INFO \\
\hline Received: 幽 February 05, 2020 \\
Published: 幽 February 13, 2020 \\
\hline
\end{tabular}

Citation: K Sangeetha, S Umamageshwari, M Bhuvaneshwari, E Devaki, R Pragadeeswari, Christie Jenifer, N Gokarneshan. Some Significant Trends in The Antimicrobial Treatment of Silk. Biomed J Sci \& Tech Res 25(4)-2020. BJSTR. MS.ID.004228.

Keywords: Antibacterial Silk; Walnut Shell; Bacteria; Biocompatibility; Natural Dye; Microwave

\section{ABSTRACT}

The article provides some useful insights on recent trends in the antimicrobial treatment of silk. The antimicrobial activity of silk fabric pretreated with Moreinga oilfera and dyed with natural coloring matter extracted from madder using microwave heating methods, has been investigated. On the one hand the dyeability was enhanced and on the other the antimicrobial activity against certain types fungi and bacteria have revealed high inhibition percent than untreated samples. The microwave method of heating adopted proves to be more economical and ecofriendly in comparison with conventional techniques. An attempt has been made to produce an antibacterial and absorbable fixation screw by adding gentamicin to silk based materials. The objective has been to avoid removal of internal fixation devices after an orthopaedic surgery caused by implant associated infections and non absorbing materials that contributed to second surgical procedure. Alum mordanted and unmordanted silk fabrics have been dyed with green walnut shell. Improved antimicrobial effect has been observed on selected strains of bacteria.

\section{Introduction}

Natural dyes have attracted attention during recent years [1,2]. Textile materials and clothing are known to be prone to microbial attack since they offer the fundamental necessities for microbial growth [3]. Natural fibres comprising of cellulose and protein, provide moisture, oxygen, nutrients and temperature for bacterial growth and multiplication. This often results in objectionable odour dermal infection, product deterioration allergic responses and often related diseases [4]. Owing to aging population and improving medical care, the use of internal fixation devices, particularly metallic materials is widespread and expected to increase in the future. But in order to remove internal fixation devices, second surgical procedures are normally resorted. A study reveals that about $5 \%$ of all orthopaedic procedures in US and nearly $81 \%$ of implants inserted for fracture fixation are removed after fracture healing which greatly increases the pain and financial burden for patients [5-7]. The demerits associated with rigid plate and screw fixation, including, infection, exposure, retained implants and pain can result in another surgery [8-12]. Antimicrobial finishes prevent the growth of microorganisms on fabrics used in wide variety of apparel, home furnishing, commercial and industrial products. Fabrics will have a longer life when treated with some type of antimicrobial finishes that reduce or prevent damage from microorganisms [13].

\section{Natural Dyed Pre-Treated Silk Having Antimicrobial Properties}

The consumers are aware of hygienic lifestyle and there is a necessity of textile product with antimicrobial properties. Many antimicrobial agents like quaternary ammonium compounds and recently nano silver are available for textile finishing [14,15]. The use of natural products such as chitosan and natural dyes for antimicrobial finishing of textiles has been widely reported $[16,17]$. For achievement of the maximum gain, an ideal antimicrobial treatment of textile should fulfil many criteria [18]. The antimicrobial agent should be effective against broad spectrum 
of bacterial and fungal species but at the same time exhibit low toxicity to consumers, e.g., not cause toxicity, allergy or irritation to the user. Chitosan comes into focus and is advocated as an ideal antimicrobial agent [19]. Morienga Olifera contributes products of excellent nutritional quality mainly due to the wide variety of it, to its exceptional medicinal properties and to its use in human feeding. It is also used as flocculent in water treatment.

Also, it is useful in the production of biodiesel, ethanol, oil and gums; as well as in the control of vectors and infections caused by microorganisms and as biopesticide. Root, flowers, bark, stem, leaves and seeds of Morienga Olifera possess antimicrobial properties. In Egypt the sowing and establishment of Morienga Olifera has increased remarkably, according to the scientific strategy followed at international level with such plant. Focus has been directed towards the investigation of the influence of the pretreatment of silk fabric with natural product as Morienga Olifera on dyeing and antimicrobial activity. Silk fabric was dyed with madder dye using microwave heating method (Figures 1-3). Antimicrobial activity of silk fabric pretreated with Moreinga olefera seed extract and dyed with madder dye was evaluated. Results show that all concentration of Moreinga olefera seed extracts enhances the antimicrobial properties of silk fabric against all tested microbes.

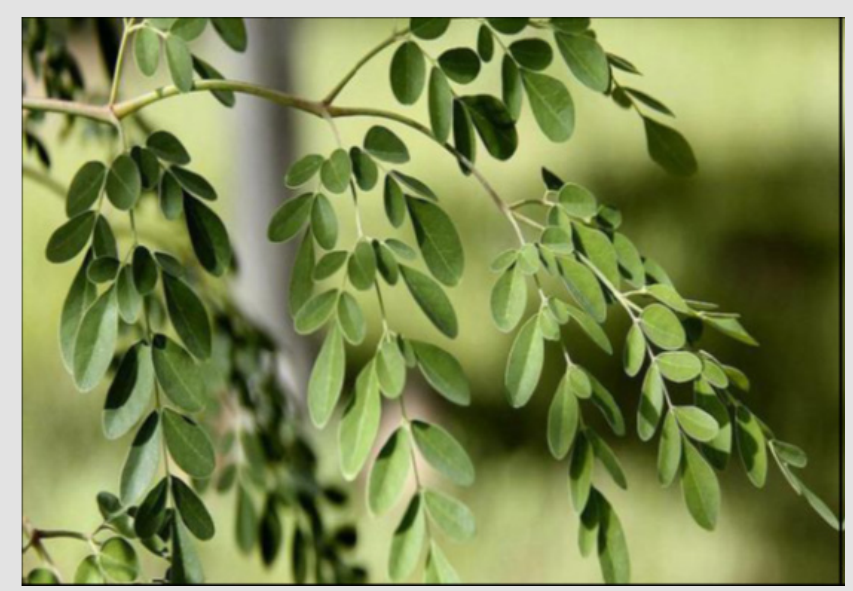

Figure 1: Moringa olifera plant.

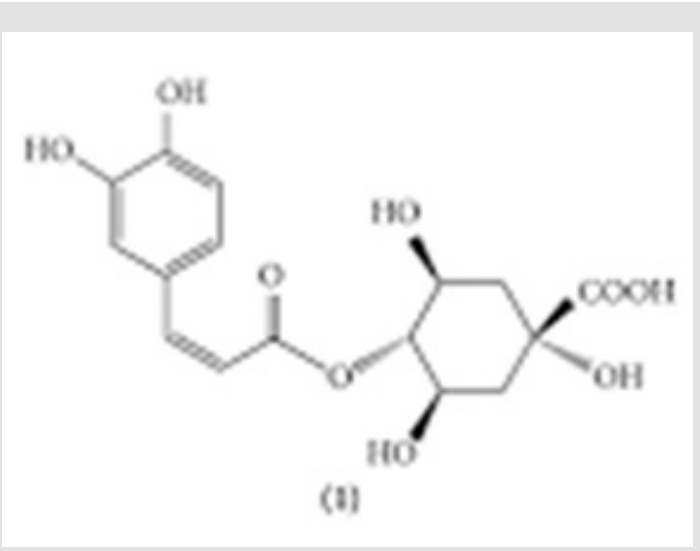

Figure 2: Chemical structure.

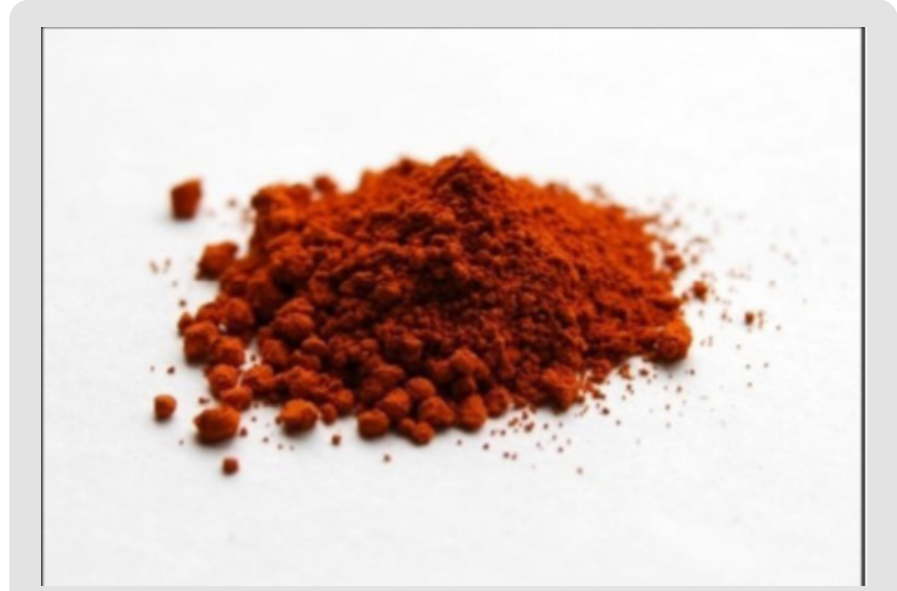

Figure 3: Madder dye.

Antimicrobial activity of silk fabric is tested in accordance to diffusion agents, test organisms such as Escherichia coli, Staphylococcus aureus and Aspergillus niger 1, 2,3 were used and the results indicate that the samples pretreated with Moreinga olefera seed extract exhibit higher inhibition percent than the untreated samples. The antimicrobial properties against E. coli (G-) was found to be greater than that of Staphylococcus aureus ( $\mathrm{G}+$ ) which can be attributed to the differences in the structure between the two types of bacteria. The antimicrobial properties of the treated samples can be attributed to treatment by Moreinga olefera. The ability of this matter to form true covalent bonds with silk fabrics leads to the improvements of the antimicrobial properties. Antimicrobial activity, expressed as growth reduction of the microorganisms, could be explained as follows: The hydroxyl groups in Moreinga olefera interfere with the bacterial metabolism by stacking at the cell surface and binding with DNA to inhibit m-RNA synthesis.

The increasing of concentration of Moreinga olefera shows more tendencies to deposit on the surface of the fabrics, resulting in hydroxyl groups more easily accessible to microorganisms. Silk fabrics treated with Moreinga olefera and dyed with the madder natural dye display high growth reduction of microbes. The pretreated silk fabrics and dyed with madder natural dye display high growth reduction of microbes compared to untreated [20]. The research proves the feasibility of high quality pretreatment with natural dye extracted from madder, thus creating new opportunities for the environment and and the fabric industry to catch up the current consumer trends.

\section{Antibacterial and Absorbable Silk Based Fixation Material in Orthopaedics}

During the past few decades, the development and use of resorbable fixation devices of differing polymer compositions including Poly-L-Lactic acid, polyglycolic acid, and polylactic co glycolic acid, a number of potential merits have been shown to reduce the need for hardware removal and the risk of growth restriction and transcranial migration [21,22]. However, identified complications of resorbable fixation devices include infections, 
self limited local inflammatory reactions, palpability, and device removal [23-28]. It has been reported that the incidence of infections ranges from 0.2 to $2 \%$, the incidence of inflammation reactions ranges from 0.7 to $14 \%$, and the incidences of all causes of plate or screw removal range from 0.3 to $4 \%$. A bioabsorbable ciprofloxacin containing bone screw has been explored to prevent biomaterial related infection but its lower strength and the abovementioned disadvantages have restricted the widespread clinical application of these resorbable implants [29].

Low load prearticular fractures such as craniao facial fractures, calcaneal fractures, and metacarpal fractures remain the best indications for their use [30-32]. It has been recently reported that silk based screws may become an option for resorbable fixation devices that overcome the limitations of conventional resorbable materials due to their impressive mechanical features, biocompatibility, ability to promote bone remodelling and environmental stability [33]. In addition, the potential utility of easy implantation, autoclave sterilization and FDA approved uses benefit their application as a medical device [34]. But, similar to other biomaterials, silk based screws may carry an elevated risk of implant- associated infections because of the formation of bacterial biofilms [34-37]. The research considered indicates that silk fibrion partly promotes the growth of S.Aureus bacteria, which may be the major disadvantage of the use of these screws as a fixation device.

The paramount importance of infection prevention should be emphasized because implant associated infections are difficult to cure due to bacterial biofilms, and in many cases, removal is the only remedy [38]. Several biomaterial surface modifications have been proposed to impart silk fibroin with antibacterial properties, such as combination with chitosan, chemical attachment of antimicrobial peptides and loading with silver nano particles [3942]. However, in clinical applications, internal fixation materials must be autoclaved for sterilization, and high temperatures may affect the antibacterial properties of antimicrobial peptides [43]. Silk based fixation materials will remain in the body for a long time, even for more than a year, but the safety of the long term and continuous release of silver nano particles in the body is not clear [44]. Furthermore, internal fixation materials require a specific material form, and mechanical strength, so these materials may be unsuitable for silk based fixation materials.

The preparation of antibacterial silk based screws has been explored, from the incorporation of an antibacterial agent, gentamicin to provide high and durable antimicrobial activity. In the research considered herein, the properties of the silk based screws containing gentamicin, such as the mechanical features, swelling properties, biocompatibility, and degradation, were tested in vitro. Furthermore, the antimicrobial activity of gentamicin loaded silk based screws was assessed for S.Aureus, and gram negative E. Coli in vitro. Finally, it was expected to obtain a resorbable and antimicrobial fixation device with high mechanical strength and impressive biocompatibility to reduce the risk of second surgery caused by infection and other complications (Figure 4). An internal fixation device is one of the most important risk factors increasing the susceptibility to infections, especially for resorbable materials. Implant-associated infections and retained implants frequently result in a second surgical procedure to remove the implants [40], which has substantial economic implications as well as possible time off work required for postoperative recovery [3]
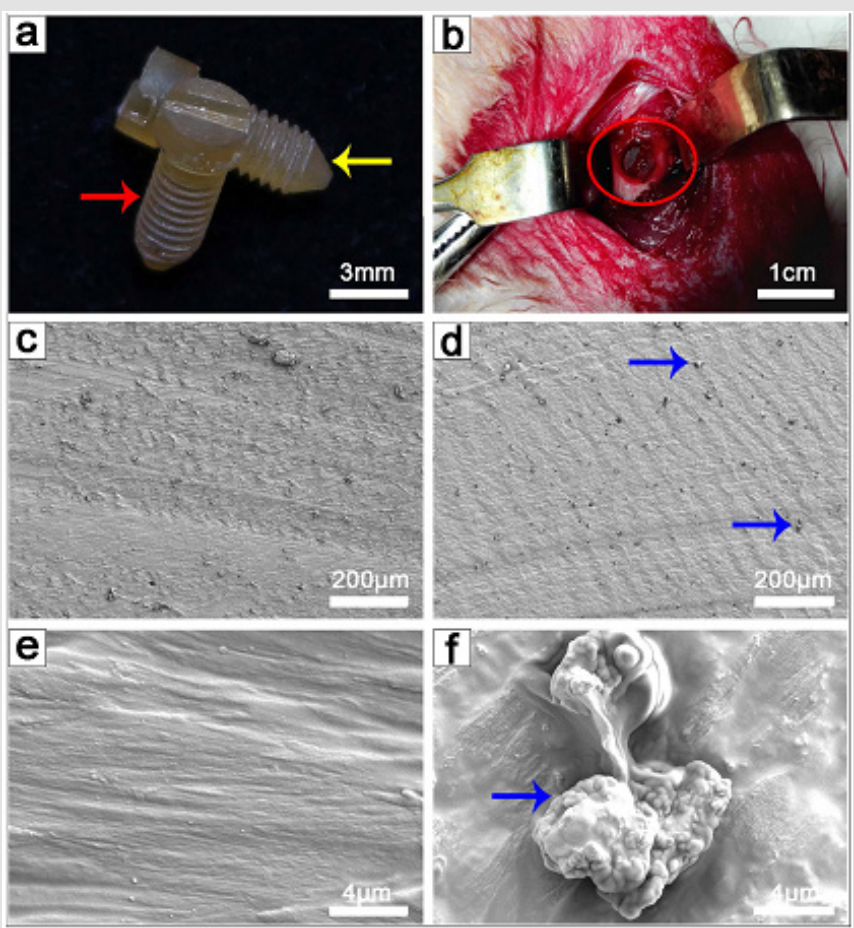

Figure 4: Images of silk screws. 
The objective of the present study was to produce an antibacterial and absorbable fixation material with potential to solve this difficult clinical problem by simply combining gentamicin and silk. In the past several decades, many studies have focused on antibacterial silk-based materials to prevent infections. The following three aspects led us to select gentamicin. Foremost, we observed that gentamicin sulfate can dissolve in silk solution uniformly as a result of its good solubility in water. Second, most clinical isolates of $S$. aureus and gram-negative rods that are thought to be mainly responsible for implant-associated infections in orthopedic surgery are sensitive to gentamicin [42]. In addition, gentamicin is one of the few thermostable antibiotics. In this study, gentamicin sulfate was successfully incorporated within silk-based screws by physical dissolution in HFIP. The presence of the gentamicin particles endowed GSS with high and durable antimicrobial activity.

On the one hand, bacterial contamination during surgery, via air or direct contact and subsequent bacterial adhesion onto the biomaterial surface, is the crucial initial step in the pathogenesis of implant-associated infections. GSS1 completely inhibited the growth of $S$. aureus and E. coli within $1 \mathrm{~h}$, whereas $6 \mathrm{~h}$ was required in other groups (GSS2, GSS3, GSS4). Hence, the rapid and high bactericidal effect of GSS is critical for reducing the risk of implant-associated infection during the perioperative period. On the other hand, the GSS are intended to provide locally sufficient drug levels while maintaining low systemic levels to avoid the risk of organ toxicity, such as hearing or kidney damage, and resistant strains [45]. Therefore, $16 \mathrm{mg}$ of gentamicin incorporated per $\mathrm{g}$ of silk (GSS1) is the most suitable concentration. In addition, the decrease in antibacterial activity after 4 weeks was likely due to an insufficient amount of gentamicin remaining in the sample to completely inhibit the bacteria.

We believe that the duration of antibacterial activity in vivo should be longer with the gentamicin distributed in the surrounding tissue as the silk degrades. Tissue damage caused by surgery and foreign body implantation further increases the susceptibility to infections in the process of fracture healing38. Therefore, the durable antimicrobial activity of GSS1 is important in preventing chronic infection to avoid implant failures or a second surgery. Interestingly, we found that PSS may promote the growth of $S$. aureus, which will increase the risk of implant-associated infection. This behavior was possibly due to the rough surface and degradation products of the PSS. Therefore, antibacterial activity must be conferred to silk fibroin by loading with gentamicin. Furthermore, local antimicrobial prophylaxis may carry a reduced risk of inducing resistant strains than the systemic therapy used in orthopedic implant surgery. Remarkable mechanical properties and excellent biocompatibility are prerequisites for load bearing biomedical implants, especially for an internal fixation device based on polymer biomaterials.
It has been shown that silk fibroin is such a natural biopolymer with high mechanical strength, biodegradability and excellent biocompatibility. However, it is unclear whether these basic features of silk will be altered after combining silk with gentamicin sulfate. Research indicates that GSS maintains the remarkable mechanical properties and excellent biocompatibility exhibited by PSS. Bending and shear forces are two of the most prominent forces for fixation pin function. The results of the three-point bending test and double-shear test demonstrated that GSS have impressive mechanical features, similar to those of PSS, sufficient to withstand loading during bone formation. Moreover, GSS and PSS have Young's modulus values of approximately $8 \mathrm{GPa}$ compared with approximately $18 \mathrm{GPa}$ for cortical bone. However, the Young's modulus of Ti-6Al-4V is $113.8 \mathrm{GPa}$, which can result in stress shielding during fracture healing. It has been reported that more flexible and absorbable fixation devices make bone healing faster and more complete.

In addition, the results of the CCK-8 assay and flow cytometry analysis indicate that there were no detrimental effects on cell proliferation or apoptosis from the PSS or GSS1. Thus, GSS exhibited good biocompatibility, similar to that of PSS, whose excellent biocompatibility was reported in previous studies. Therefore, incorporating gentamicin sulfate does not change the biocompatibility of silk protein. The degradation of PSS was consistent with a second-order polynomic trendline, which agrees with previous studies. Interestingly, the degradation rate of GSS1 was apparently faster than that of PSS and was consistent with a third-order polynomic trendline. One explanation for this difference may be associated with the voids that increased the surface area exposed to the enzyme. We may assume that these voids are due to the dissolution of gentamicin particles, resulting in a porous structure because the sizes of the voids were similar to those of the gentamicin particles.

If this is the case, the degradation rate of GSS may be tunable by changing the number and size of the gentamicin particles. Furthermore, a combination of the surface roughness caused by the rapid degradation of GSS1 and porosity favored human bone marrow-derived mesenchymal stem cell differentiation toward bone-like tissue. In addition, rapid degradation and bone-like tissue are beneficial to a gradual transfer of the load-bearing burden to the developing tissue during fracture healing, which supports the restoration and maintenance of tissue function over the life of the patient. Generally, after approximately months, bone union has gained enough strength and rigidity, corresponding to the time at which the GSS were approximately $60 \%$ of the mass remaining in vitro. We deduced that the PSS samples would completely degrade in vitro after approximately 8 months according to the degradation data, and the time required for GSS1 to completely degrade is approximately 5 months. 
However, these approximations cannot directly represent degradation in vivo due to the complex environment in the body, such as the presence of various enzymes and cell types. In the future, research on in vivo degradation will need to be explored. We believe that GSS can be an optimal fixation material whose initial strength can provide excellent fixation with a mass loss profile that is suitable for the bone-healing process. The rapid swelling of the silk screws results in a reduction in mechanical strength, which may cause the implantation process to fail. In addition, the increase in the diameter of the screws during the operation will make it difficult for the surgeon to implant the screws. Therefore, the decreased water-absorbing capacity of GSS1 in is beneficial to the implantation of the screw by the surgeon. For at least $30 \mathrm{~min}$, the diameter of GSS1 did not increase significantly when it came into contact with water in the body, which is a sufficient time for the surgeon to implant the screw.

However, the limitation of these GSS is the size of the screws. When the sizes of the molds were increased to increase the diameter of the blanks and the screws, there were bubbles in the silk blanks that would affect the functioning and mechanical stability of the screws. Future research should be conducted to verify the features of GSS in vivo, such as their antibacterial ability, regulation of degradation and biocompatibility, and to investigate their detailed mechanism. Pure silk based screws promoted the growth of S.Aureus in vitro. To prevent implant associated infections after fixation surgery, gentamicin was successfully incorporated into silk based screws [45]. Gentamicin loaded silk based screws not only retained the impressive mechanical features and biocompatibility of pure silk based screws but also exhibited high and durable antimicrobial activity against S.Aureus and E.Coli in vitro. The degradation rate of gentamicin based screws increased, which was related to the dissolution of gentamicin particles, leaving a porous structure. In addition, the decreased water absorption of gentamicin based screws will give the surgeon more time to implant this screw. Findings reveal that the antibacterial silk based fixation material can overcome the limitations of metal and traditionally resorbable devices, with great potential for use in orthopaedic implants to reduce the incidence of second surgical procedures for a given clinical application.

\section{Conclusion}

Silk fabric pretreated with Morienga Olifera exhibit higher inhibition percent than untreated samples with regard to antimicrobial activity against selected bacteria and fungi, besides other benefits such as better dyeability. The antimicrobial activity with some kinds of Bacteria and Fungi were tested, and the results indicated that the samples pretreated exhibit higher inhibition percent than the untreated samples. An antibacterial and absorbable fixation screw by adding gentamicin to silk-based materials has been developed. The antibacterial activity was assessed against Staphylococcusaureus (S. aureus) and Escherichia coli (E. coli) in vitro by plate cultivation and scanning electron microscopy (SEM). The properties, such as the mechanical features, swelling properties, biocompatibility and degradation, of gentamicin-loaded silk-based screws (GSS) in vitro, have also been studied. The GSS showed significant bactericidal effects against $S$. aureus and $E$. coli. The antibacterial activity remained high even after 4 weeks of immersion in protease solution. In addition, the GSS maintained the remarkable mechanical properties and excellent biocompatibility of pure silk-based screws (PSS). Interestingly, after gentamicin incorporation, the degradation rate and water-absorbing capacity increased and decreased, respectively. These GSS provide both impressive material properties and antibacterial activity and have great potential for use in orthopedic implants to reduce the incidence of second surgeries.

\section{References}

1. Bechtold T, Musak R, Ganglberger E, Geissler S (2006) Extraction of natural dyes for textile dyeing from colored plant wastes released from the food and beverage industry. Journal of science food and agriculture 86(2): 233-242.

2. Teli MD, Paul R, Pardesi PD (2000) Natural dyes: Classification, chemistry and extraction methods Part I. Journal of Colorage 47(12): 43-48.

3. Ali NF, RSR EL Mohamedy, EM El Khatib (2011) Antimicrobial activity of wool fabric dyed with natural dyes. Research journal of textile and apparel 15: 1-10.

4. Cardamone JM (2002) Proteolytic activity of Aspergillus flavus on wool. AATCC Reviews 5: 30-35.

5. Rutkow IM (1986) Orthopaedic operations in the united states, 1979 through 1983. Journal of bone joint surgery 68(5): 716-719.

6. Bostman O, Pihlajamaki H (1996) Routine implant removal after fracture surgery: a potentially reducible consumer of hospital resources in trauma units. Journal of Trauma 41(5): 846-849.

7. Busam ML, Esther RJ, Obremsky WT (2006) Hardware removal: Indications and expectations. Journal of American academy of orthopaedic surgery 14(2): 113-120.

8. Campbell CA, Lin KY (2009) Complications of rigid internal fixation. Craniomaxillofac Trauma reconstruction 2(1): 41-47.

9. Francel TJ, Birley BC, Ringleman PR, Manson PN (1992) The fate of plates and screws after facial fracture reconstruction. Plastic reconstruction surgery $90(4)$ : 568-573.

10. Mansion PN, Crawley WA, Yaremchuk MJ, Rochman GM, Hoopes JE, et al. (1985) Midface fractures. Advantages of immediate extended open reduction and bone grafting. Plastic reconstruction surgery 76(1): 1-12.

11. Orringer JS, Barcelona V, Buchmann SR (1998) Reasons for removal rigid internal fixation devices in craniofacial surgery. Journal of craniofacial surgery 9(1): 40-44.

12. Lovald S, Mercer D, Hanson J, Cowgill I, Erdman M, et al. (2011) Complications of hardware removal after open reduction and internal fixation of humeral fractures. Journal of Trauma 70(5): 1273-1277.

13. Hashem M, Ibrahim NA, El Sayed WA, El Hussainy S, El Ennany E (2009) Enhancing antimicrobial properties of dyed and finished cotton fabrics. Carbohydrate polymers 78(3): 502-510.

14. Hebeish A, El Naggar ME, Fouda MMG, Ramadan MA, Al Deyab SS (2011) Highly effective antibacterial textiles containing green synthesized silver nano particles. Carbohydrate Polymer 86(2): 936-940.

15. Hebeish A, El Rafie MH, El Shaikh MA, Seleem AA, El Naggar ME (2014) Antimicrobial wound dressing and anti-inflammatory efficacy of silver 
nano particles. International journal of biology and macromolecules 65 509-515.

16. Shin Y, Yoo DI, Jang J (2010) Molecular weight effect on antimicrobial activity of chitosan treated cotton fabrics. Journal of applied polymer science 80(13): 2495-2591.

17. Singh R, Jain A, Panwar S, Gupta D, Khare SK (2005) Antimicrobial activity of some natural dyes. Dyes and Pigments 66(2): 99-102.

18. Williams JF, Cho U (2005) Antimicrobial functions for synthetic fibres: Recent developments. AATCC Review 5(4): 17-21.

19. Hebeish AAI, NF Ali, JI Abd El Thalouth (2012) Green strategy for development of antimicrocial printed textile fabrics. Research journal of textile and apparel 16: 77-81.

20. NF Ali, EM El Khatib, RSR El Mohamedy (2015) The antimicrobial activity of pretreated silk fabrics dyed with natural dye. International journal of current microbiology and applied science 4(6): 1166-1173.

21. Zhang J, Ebrahiem N, Lause GE, Xiao B, Xu R (2011) A comparison of absorbable screws and metallic plates in treating calcaneal fractures: a prospective randomised trial. Journal of Trauma Acute care surgery 72(2): E106-110.

22. Hovis WD, Watson JT, Bucholz RW (1998) Biochemical and biomechanical properties of bioabsorbable implants used in fracture fixation. Techniques in orthopaedics 13(2): 123-129.

23. Bell RB, Kindsfater CS (2006) The use of biodegradable plates and screws to stabilize facial fractures. J Oral Maxillofac Surg 64(1): 31-39.

24. Sanger C, Soto A, Mussa F, Sanzo M, Sardo L, et al. (2007) Maximizing results in craniofacial surgery with bioresorbable fixation devices. J Craniofac Surg 18(4): 926-930.

25. Böstman OM (1991) Absorbable implants for the fixation of fractures. J Bone Joint Surg Am 73(1): 148-153.

26. Bostman O, Hirvensalo E, Makinen J Rokkanen P (1990) Foreign-body reactions to fracture fixation implants of biodegradable synthetic polymers. J Bone Joint Surg Br 72(4): 592-596.

27. Bostman OM, Pihlajamaki HK (1998) Late foreign-body reaction to an intraosseous bioabsorbable polylactic acid screw. A case report. J Bone Joint Surg Am 80(12): 1791-1794.

28. Waris E, Ashammakhi N, Happonen H, Raatikainen T, Kaarela O, et al. (2003) Bioabsorbable miniplating versus metallic fixation for metacarpal fractures. Clin Orthop Relat Res 410: 310-319.

29. Mäkinen TJ, Veiranto M, Knuuti J, Jalava J, Törmälä P, et al. (2005) Efficacy of bioabsorbable antibiotic containing bone screw in the prevention of biomaterial-related infection due to Staphylococcus aureus. Bone 36(2): 292-299.

30. Eppley BL (2005) Use of resorbable plates and screws in pediatric facial fractures. J Oral Maxillofac Surg 63(3): 385-391.

ISSN: 2574-1241

DOI: 10.26717/BJSTR.2020.25.004228

N Gokarneshan. Biomed J Sci \& Tech Res

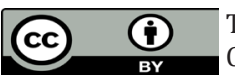

This work is licensed under Creative Commons Attribution 4.0 License

Submission Link: https://biomedres.us/submit-manuscript.php
31. Eppley BL, Sadove AM, Havlik RJ (1997) Resorbable plate fixation in pediatric craniofacial surgery. Plast Reconstr Surg 100(1): 1-7 discussion 8-13.

32. Dumont C, Fuchs M, Burchhardt H, Appelt D, Bohr S, et al. (2007) Clinical results of absorbable plates for displaced metacarpal fractures. J Hand Surg Am 32(4): 491-496.

33. Perrone GS, Leisk GG, Lo TJ, Moreau JE, Haas DS, et al. (2014) The use of silk-based devices for fracture fixation. Nat Commun 5: 3385.

34. Kund B, Rajkhowa R, Kundu SC, Wang X (2013) Silk fibroin biomaterials for tissue regenerations. Adv Drug Deliv Rev 65(4): 457-470.

35. Nichols RL, Raad II (1999) Management of bacterial complications in critically ill patients: surgical wound and catheter-related infections. Diagn Microbiol Infect Dis 33(2): 121-130.

36. Vande Vord PJ, Nasser S, Wooley PH (2005) Immunological responses to bone soluble proteins in recipients of bone allografts. J Orthop Res 23(5): 1059-1064.

37. Zhang W, Paul K Chu, Junhui Ji, Yihe Zhang, Ricky KY Fu, et al. (2006) Antibacterial properties of plasma-modified and triclosan or bronopol coated polyethylene. Polymer 47(3): 931-936.

38. Costerton JW, Stewart PS, Greenberg EP (1999) Bacterial Biofilms: A Common Cause of Persistent Infections. Science 284(5418): 1318-1322.

39. Van De Belt H, Neut D, Schenk W, Van Horn JR, Van der Mei HC, et al. (2001) Infection of orthopedic implants and the use of antibiotic-loaded bone cements. A review. Acta Orthop Scand 72(6): 557-571.

40. Cai ZX, Xiu Mei Mo, Kui-hua Zhang, Lin peng Fan, An lin Yin, et al. (2010) Fabrication of chitosan/silk fibroin composite nanofibers for wounddressing applications. Int J Mol Sci 11(9): 3529-3539.

41. Bai L, Liangjun Zhu, Sijia Min, Lin Liu, Yurong Cai, et al. Surface modification and properties of Bombyx mori silk fibroin films by antimicrobial peptide. Appl Surf Sci 254(10): 2988-2995.

42. Fei X, Jia M, Du X, Yang Y, Zhang R, et al. (2013) Green synthesis of silk fibroin-silver nanoparticle composites with effective antibacterial and biofilm-disrupting properties. Biomacromolecules 14(12): 4483-4488.

43. Uttayarat P, Suwimol Jetawattana, Phiriyatorn Suwanmala, Jarurattana Eamsiri, Theeranan Tangthong, et al. (2012) Antimicrobial electrospun silk fibroin mats with silver nanoparticles for wound dressing application. Fibe Polym 13(8): 999-1006.

44. Chen Y, Vasil AI, Rehaume L, Mant CT, Burns JL, et al. (2006) Comparison of biophysical and biologic properties of alpha-helical enantiomeric antimicrobial peptides. Chem Biol Drug Des 67(2): 162-173.

45. Chenglong Shi, Xiaobing Pu, Guan Zheng, Xinglong Feng, Xuan Yang, et al (2016) An antibacterial and absorbable silk-based fixation material with impressive mechanical properties and biocompatibility. An antibacterial and Sci Rep 6: 37418.

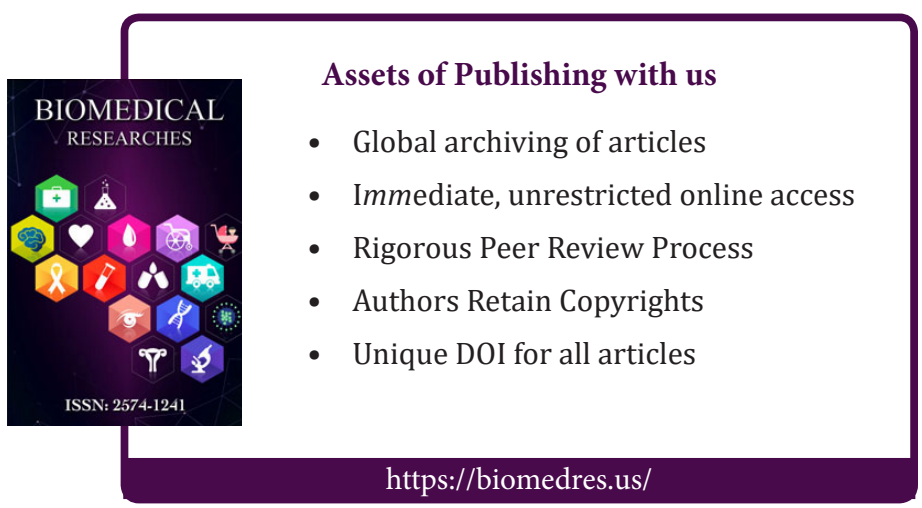

Copyright@ N Gokarneshan | Biomed J Sci \& Tech Res | BJSTR. MS.ID.004228. 